\title{
Uso de tanque séptico e filtro de areia no tratamento de esgoto e benefícios do filtro anaeróbio
}

\section{Use of septic tank and sand filter in sewage treatment and the benefits of anaerobic filter}

\author{
Data de entrada: \\ $14 / 04 / 2020$ \\ - Data de aprovação: \\ 22/05/2020
} Adriano Luiz Tonetti ${ }^{1 *}$ | Luana Mattos de Oliveira Cruz ${ }^{1}$ | Bianca Graziella Lento Araujo Gomes ${ }^{1}$ | DOI: https://doi.org/10.36659/dae.2021.064
Isabel Campos Salles Figueiredo'

ORCID ID

Tonetti AL (iD https://orcid.org/0000-0003-0910-401X

Gomes BGLA (iD) https://orcid.org/0000-0001-5314-3724
Cruz LMO iD https://orcid.org/0000-0003-3795-9111

Figueiredo ICS (D) https://orcid.org/0000-0003-0940-0556

\section{Resumo}

Foram estudados reatores anaeróbios associados a um filtro de areia para o tratamento do esgoto doméstico de uma empresa de Campinas (São Paulo). Na Etapa 1 houve a associação do tanque séptico a um filtro de areia, e na Etapa 2 foi pesquisada a combinação do tanque séptico a um filtro anaeróbio e filtro de areia. $O$ resultado encontrado foi que, ao associar o tanque séptico ao filtro de areia, eram necessárias 10 semanas até o entupimento do leito de areia. O filtro anaeróbio preenchido com cascas de coco verde (Cocos nucifera) trouxe uma ampliação desse período para 20 semanas. A menor manutenção pode ter sido ocasionada pela diminuição em $70 \pm 11 \%$ na concentração de sólidos suspensos propiciada pelo filtro anaeróbio. $O$ efluente gerado sempre apresentou baixos valores de turbidez ( $<10$ UT) e DBO $\left(<17 \mathrm{mgL}^{-1}\right)$. A nitrificação saltou de 10,0 \pm 9,3\% quando havia a associação do tanque séptico com o filtro de areia para $76,0 \pm 16,7 \%$ do N-Total quando foi introduzido o filtro anaeróbio.

Palavras-chave: Saneamento. Descentralizado. Rural. Isolado. Esgoto. Anaeróbio.

\section{Abstract}

We studied anaerobic reactors associated with a sand filter for domestic sewage treatment from a company in Campinas (São Paulo). In phase 1, the septic tank was associated with a sand filter and in phase 2, the combination of the septic tank with the anaerobic filter, filled up with coconut shells (Cocos nucifera), and a sand filter was investigated. It was found that when associating the septic tank with the sand filter, it took 10 weeks until the sand filter became clogged. When using the anaerobic filter this period was extended to 20 weeks. The lower maintenance may have been caused by the decrease of $70 \pm 11 \%$ in the concentration of suspended solids provided by the anaerobic filter. The effluent had low values of turbidity $\left(<10\right.$ UT) and BOD $\left(<17 \mathrm{mgL}^{-1}\right)$. The nitrification of the $\mathrm{N}$-Total increased from $10.0 \pm 9.3 \%$, when there was an association only with the septic tank and the sand filter, to $76.0 \pm$ $16.7 \%$ when the anaerobic filter was introduced.

Keywords: Sanitation. Decentralized. Rural. Isolated. Wastewater. Anaerobic.

\footnotetext{
1 Universidade Estadual de Campinas - Campinas - São Paulo - Brasil.

* Autor correspondente: tonettiaunicamp.br.
} 


\section{INTRODUÇÃO}

A problemática do saneamento básico no Brasil pode ser medida pelo número de municípios existentes no país sem qualquer tipo de serviço de esgotamento sanitário. Segundo o IBGE (2008), das 5.507 cidades brasileiras $52,2 \%$ estavam nessa situação calamitosa. Os municípios que se encontram em tal conjuntura são considerados pequenos em sua maioria, possuindo uma população inferior a 10.000 habitantes e correspondendo a $48,37 \%$ de todas as cidades brasileiras, nos quais $47,09 \%$ dos cidadãos vivem na zona rural.

A maior parte dessas localidades lança seus dejetos in natura nos corpos hídricos ou no solo, comprometendo a qualidade da água utilizada para o abastecimento, irrigação e recreação (FIGUEIREDO et al., 2019). Deve-se buscar algum tipo de tratamento desses esgotos que seja adequado a tais casos, permitindo o desenvolvimento de uma tecnologia de grande relevância nacional. Os processos anaeróbios contribuiriam para a solução desse problema. Sua operação seria baseada no gerenciamento da água residuária na própria origem, tornando-se uma opção de tratamento para pequenas localidades, casas individuais, condomínios, comunidades isoladas, indústrias ou no pequeno comércio onde o gasto para conexão com uma rede pública de esgoto seria alto.

$O$ tanque séptico seria uma alternativa que atenderia a tais requisitos, sendo amplamente utilizado em todo o mundo. Seu enorme uso deve-se à simplicidade na construção e na operação (NBR $7229,1993)$. Para a complementação do tratamento, a NBR 13969 (1997) cita a associação do tanque séptico ao filtro anaeróbio, o qual é um tipo de reator caracterizado pela presença em seu interior de um material suporte estacionário e inerte, onde a biomassa adere-se ou fica retida nos interstícios, formando um biofilme que degrada o substrato contido na água residuária (YOUNG e MCCARTY, 1969).

Segundo van Haandel e Lettinga (1994), uma das barreiras para a adoção dos filtros anaeróbios em escala real é o custo do material de enchimento, que pode ter a mesma ordem de grandeza do valor da própria construção do reator. Desse modo, estudando sistemas de tratamento de esgotos acessíveis a comunidades carentes, pesquisadores constataram que os anéis de bambu (TONETTI et al., 2011 e CAMARGO e NOUR, 2001) e cascas de coco verde (DE OLIVEIRA CRUZ et al., 2013; DE OLIVEIRA CRUZ et al., 2018; DE OLIVEIRA CRUZ et al., 2019) são leves e facilmente encontrados nas regiões brasileiras, permitindo que filtros anaeróbios tenham seus custos reduzidos com esses materiais como meio suporte.

Um problema relacionado à tecnologia anaeróbia refere-se à incapacidade de geração de um efluente que atenda aos padrões legais, demandando um pós-tratamento que complete a remoção da matéria orgânica, nutrientes e patógenos (CHERNICHARO, 2008). Neste caso, os filtros de areia seriam uma indicação adequada para cumprir tal função, mantendo o baixo custo e garantindo um efluente com excelente qualidade.

O funcionamento dos filtros de areia se baseia na aplicação intermitente de afluente sobre a superfície de um leito de areia (MAGALHÃES et al., 2016). Durante a infiltração do líquido ocorre a purificação por mecanismos físicos, químicos e biológicos (AUSLAND et al., 2002). 0 tratamento físico é resultante da filtração propiciada pela areia, influenciando principalmente a remoção de sólidos suspensos (MENORET et al., 2002), enquanto o químico se processa pela adsorção de determinados compostos. Entretanto, a purificação depende principalmente da oxidação bioquímica que ocorre no contato do afluente com a cultura biológica. 
A NBR 13969 (1997) recomenda que, ao se utilizar o filtro de areia no pós-tratamento de efluente do tanque séptico, a taxa de aplicação limitese a $100 \mathrm{Lm}^{-2} \mathrm{dia}^{-1}$. Caso seja proveniente de um processo aeróbio, dobra-se esse valor. Apesar de a USEPA (United States Environmental Protection Agency) ser uma agência ambiental de um país com clima mais frio, recomenda taxas superiores aos da norma brasileira, variando entre $80 \mathrm{e}$ $200 \mathrm{Lm}^{-2} \mathrm{dia}^{-1}$ quando a alimentação provém do tanque séptico e de 200 a $400 \mathrm{Lm}^{-2} \mathrm{dia}^{-1}$, se originária do filtro aeróbio.

Em um projeto piloto, Tonon et al. (2015) empregaram em filtros de areia taxas de aplicação superiores a $500 \mathrm{Lm}^{-2} \mathrm{dia}^{-1}$ de efluente anaeróbio, obtendo no líquido final valores superiores a $6 \mathrm{mgL}^{-1}$ de oxigênio dissolvido (OD), turbidez abaixo de 2 UT, valores de demanda química de oxigênio (DQO) inferiores a $80 \mathrm{mgO}_{2} \mathrm{~L}^{-1}$, demanda bioquímica de oxigênio (DBO) que não superou $31 \mathrm{mgL}^{-1}$ e uma completa nitrificação.

Tendo essa fundamentação, a presente pesquisa buscou avaliar duas conjugações diferentes de reatores aplicáveis ao saneamento descentralizado e rural: a) a associação do tanque séptico ao filtro de areia; b) a combinação do tanque séptico ao filtro anaeróbio e filtro de areia. A comparação dessas duas alternativas foi baseada na avaliação de parâmetros físicos, químicos e biológicos e em sua manutenção.

\section{METODOLOGIA}

Esta pesquisa foi desenvolvida na empresa Villa Stone Comércio e Indústria de Materiais Básicos para Construção Limitada, localizada em Campinas (São Paulo). A empresa produzia diversos tipos de pisos para calçamento e possuía 10 funcionários, tendo a perspectiva de no futuro atingir 20 operários. 0 esgoto utilizado no projeto era proveniente de atividades domésticas, relacionadas à higiene dos funcionários, não adentrando no sistema a parcela do efluente industrial.

\subsection{Tanque Séptico}

Após o início da operação do sistema, o esgoto gerado foi coletado e encaminhado para o tanque séptico com câmara única, o qual foi construído com anéis pré-moldados de concreto, tendo diâmetro interno de $1,90 \mathrm{~m}$ e profundidade total de $2,34 \mathrm{~m}$ e volume útil de $4,30 \mathrm{~m}^{3}$. O projeto foi baseado na NBR 7229 (1993) e no número de funcionários que existirá na empresa quando houver sua plena capacidade. Para isso foi adotada a Eq. 1 e as considerações expostas na Tabela 1.

$V=1000+N \cdot\left(C T+K . L_{F}\right)$

Sendo: $\mathrm{V}$ o volume útil, $\mathrm{N}$ o número de pessoas contribuintes, $\mathrm{C}$ a contribuição de despejos, T o período de detenção, $\mathrm{K}$ a taxa de acumulação de lodo digerido e $L_{\mathrm{f}}$ a contribuição de lodo fresco.

Tabela 1 - Dados para a construção do tanque séptico e filtro anaeróbio.

\begin{tabular}{|c|c|c|c|}
\hline Item & Unidade & Tanque Séptico & Filtro Anaeróbio \\
\hline Pessoas Contribuintes (N) & Funcionários & 20 & 20 \\
\hline Contribuição de Despejos (C) & L/funcionários.dia & 70 & 70 \\
\hline Período de Detenção (T) & Dia & 2 & $1\left(15 \mathrm{a} 25^{\circ} \mathrm{C}\right)$ \\
\hline $\begin{array}{c}\text { Taxa de Acumulação de Lodo } \\
\text { Digerido (K) }\end{array}$ & $\mathrm{dia}^{-1}$ & 57 & - \\
\hline Contribuição de Lodo Fresco $\left(L_{f}\right)$ & L/funcionários.dia & 0,30 & - \\
\hline Volume Calculado (V) & $\mathrm{m}^{3}$ & 4,14 & 2,24 \\
\hline Volume Adotado (V) & $\mathrm{m}^{3}$ & 4,30 & 1,57 \\
\hline
\end{tabular}


Observa-se uma pequena discrepância entre o volume calculado e o volume adotado. Isso se deveu ao uso de anéis pré-moldados de concreto, que impediam a obtenção do valor exato; assim, optou-se por um volume ligeiramente superior.

\subsection{Filtro Anaeróbio}

0 esgoto entrava pela parte inferior do filtro anaeróbio construído com anéis pré-moldados de concreto, tendo diâmetro interno de 1,38 m e profundidade total de $2,42 \mathrm{~m}$. O volume útil era de $1,57 \mathrm{~m}^{3}$, tendo sido dimensionado baseando-se na NBR 13969 (1997). Para isso empregou-se a Eq. 2 e as considerações expostas na Tabela 1.

$V_{u}=1,6 \cdot N \cdot C \cdot T$
Sendo: $\mathrm{V}_{\mathrm{u}}$ o volume útil, $\mathrm{N}$ o número de pessoas contribuintes, $\mathrm{C}$ a contribuição de despejos e $\mathrm{T}$ o tempo de detenção hidráulica.

Foi adotado para o filtro anaeróbio um volume inferior ao sugerido pela norma brasileira, sendo que essa medida baseia-se nos trabalhos de Alem Sobrinho e Said (1991); Tonetti et al. (2011); De Oliveira Cruz et al. (2018); De Oliveira Cruz et al. (2019), os quais obtiveram resultados satisfatórios para a remoção de matéria orgânica com a adoção de tempos de detenção hidráulica inferiores aos sugeridos pela NBR 13969 (1997).

No presente estudo, o material suporte adotado no filtro anaeróbio foi casca de coco verde da espécie Cocos nucifera, que anteriormente à sua colocação no interior do reator teve cada unidade dividida em quatro partes (Fig. 1).
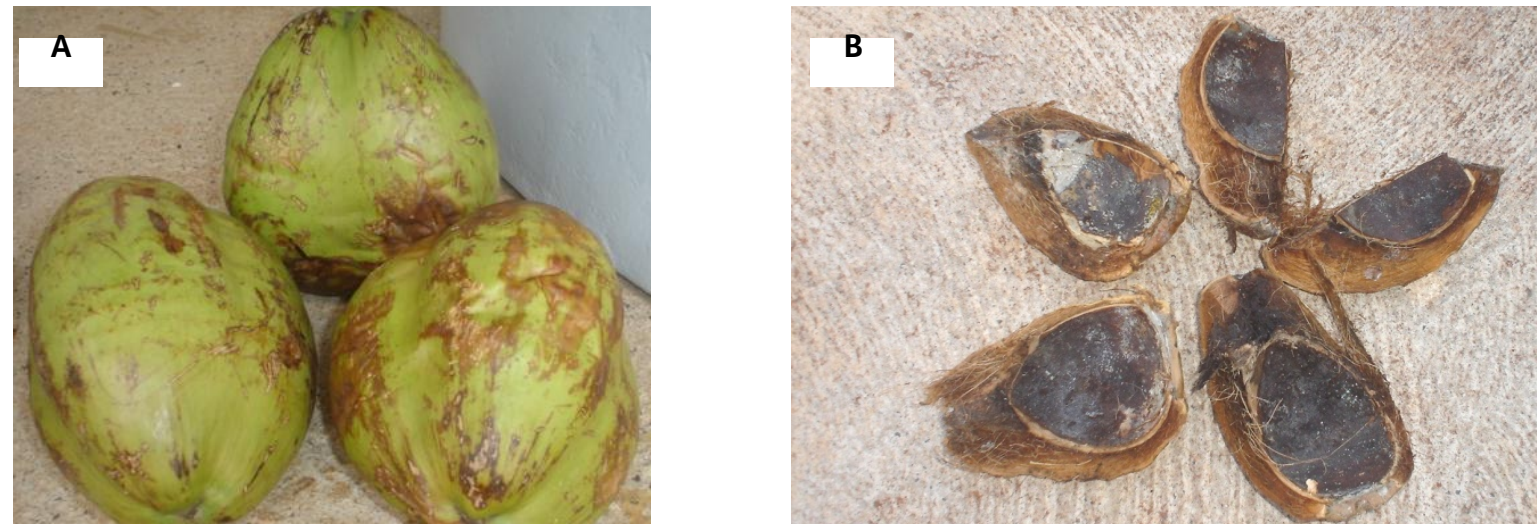

Figura 1 - Cascas de coco verde da espécie Cocos nucifera.

\subsection{Filtro de Areia}

O líquido que deixava o filtro anaeróbio era direcionado a uma caixa sifonada (Fig. 2), a qual tinha formato quadrado com largura de $0,30 \mathrm{~m}$ e com volume útil de $0,025 \mathrm{~m}^{3}$. A adoção desse dispositivo visava uma aplicação de afluente de forma intermitente, garantindo que o leito de areia mantivesse uma característica aeróbia de tratamento. Assim, somente após atingir o volume de $0,025 \mathrm{~m}^{3}$ havia a formação de um sifão que garantia a aplicação desse volume de líquido no filtro de areia. 


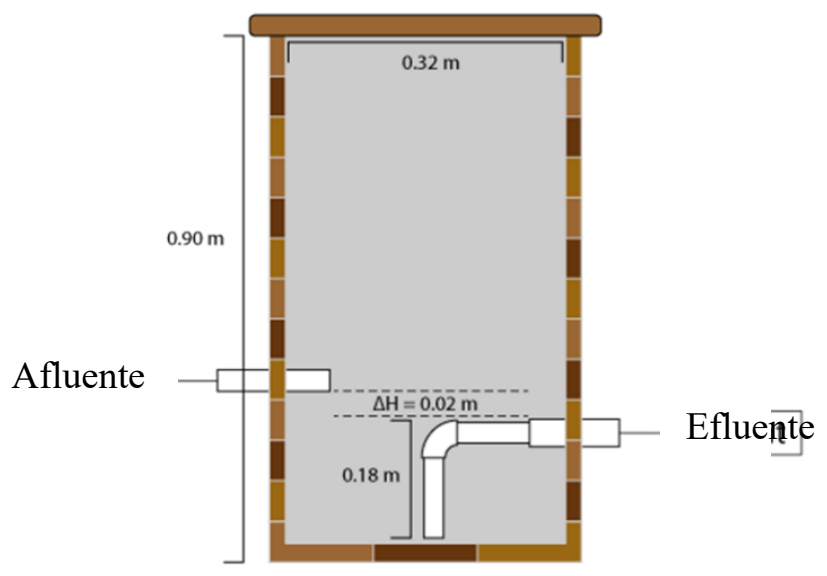

Figura 2 - Esquema e foto da caixa sifonada adotado na pesquisa (DE OLIVEIRA CRUZ et al., 2019).

Antes que o líquido encaminhado pela tubulação oriunda da caixa sifonada atingisse a superfície dos leitos de areia, havia seu choque com uma placa quadrada de madeira com $0,20 \mathrm{~m}$ de comprimento.

O filtro de areia foi construído com anéis pré-fabricados de concreto, com diâmetro interno de $1,90 \mathrm{~m}$, possibilitando uma área superficial de $2,84 \mathrm{~m}^{2}$. No tocante ao leito de tratamento seguiu-se um dimensionamento baseado na pesquisa desenvolvida por Tonetti (2008), conforme apresentado na Tabela 2.

Tabela 2 - Dados para a construção do filtro de areia baseados em Tonetti (2008).

\begin{tabular}{|c|c|c|}
\hline Item & Unidade & $\begin{array}{c}\text { Valor } \\
\text { Adotado }\end{array}$ \\
\hline Pessoas Contribuintes (N) & Funcionários & 20 \\
\hline Contribuição de Despejos (C) & L/funcionários.dia & 70 \\
\hline Volume Diário de Contribuição (V) & $\mathrm{L}$ & 1400 \\
\hline $\begin{array}{c}\text { Área Superficial para Taxa de } \\
\text { 500 L.m }{ }^{-2} \text {.dia }\end{array}$ & $\mathrm{m}^{2}$ & 2,80 \\
\hline Área Superficial Adotada & $\mathrm{m}^{2}$ & 2,84 \\
\hline
\end{tabular}

Para a composição do leito foram empregadas três camadas estratificadas a partir da base do reator (Fig. 3). A primeira possui 0,20 m de profundidade e foi composta por brita 2, com diâmetro efetivo $\left(D_{10}\right)$ de $16,12 \mathrm{~mm}$, coeficiente de desuniformidade $\left(C_{D}\right)$ de 1,89 e coeficiente de vazios $\left(C_{v}\right)$ de 45,80 $\pm 0,40 \%$. Logo acima estava a camada formada por brita 1 com $D_{10}$ igual a 7,51 mm, CD de 1,66 e Cv de 44,08 \pm 0,38\%, tendo $0,05 \mathrm{~m}$ de profundidade. Esse material objetivou sustentar a areia, impedindo que suas partículas fossem arrastadas para fora da estrutura do sistema.

Quanto ao leito de areia, foi adotada profundidade de 0,40 m. A areia empregada foi a popularmente denominada de média, classificada de acordo com procedimento apresentado pela NBR 6502 (1995), possuindo um diâmetro efetivo de $0,18 \mathrm{~mm}$, coeficiente de desuniformidade de 3,14 e coeficiente de vazios de $28,58 \pm 0,87 \%$.

A taxa de aplicação ao longo de um dia adotada no dimensionamento do filtro de areia excedia aquela sugerida pela norma brasileira (NBR 13969, 1997). Essa particularidade foi baseada na pesquisa desenvolvida por Tonon et al. (2015), que constataram que mesmo com disposições maiores que $500 \mathrm{Lm}^{-2} \mathrm{dia}^{-1}$, valor superior ao limite máximo recomendado pela norma, havia a geração de um efluente adequado aos padrões de lançamento. 


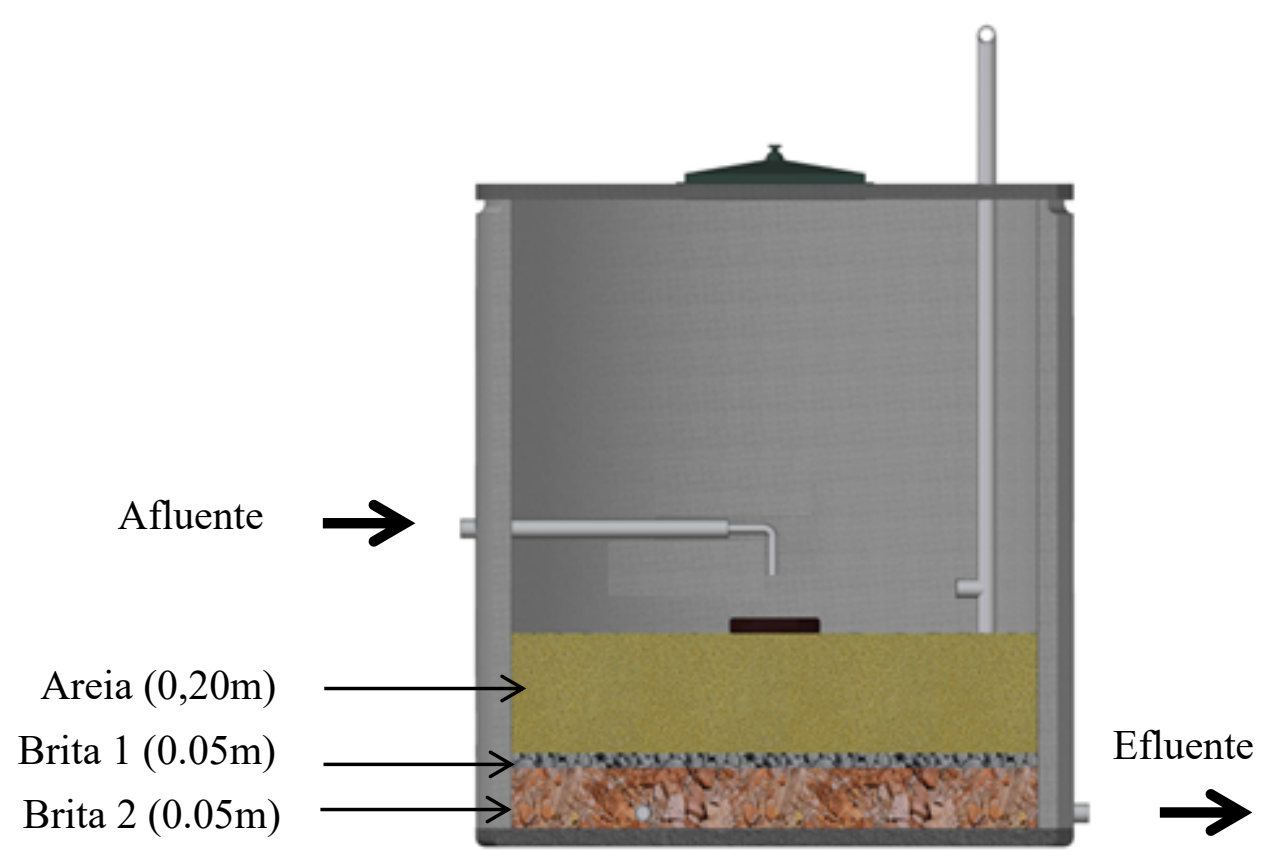

Figura 3 - Esquema do filtro de areia adotado na pesquisa (DE OLIVEIRA CRUZ et al., 2019).

\subsection{Aspectos operacionais e etapas do projeto}

$\mathrm{O}$ projeto foi desenvolvido em duas Etapas. $\mathrm{Na}$ Etapa 1 foi avaliada a associação do tanque séptico com o filtro de areia. Na Etapa 2 foi estudada a associação do tanque séptico ao filtro anaeró- bio e ao filtro de areia (Tabela 3). Cada etapa foi operada até que ocorresse o entupimento do leito de areia. Em cada uma delas isso se deu 3 vezes. Após cada entupimento era feita a raspagem da camada superficial $(5 \mathrm{~cm})$ e imediatamente era reiniciada a aplicação do afluente.

Tabela 3 - Etapas do projeto.

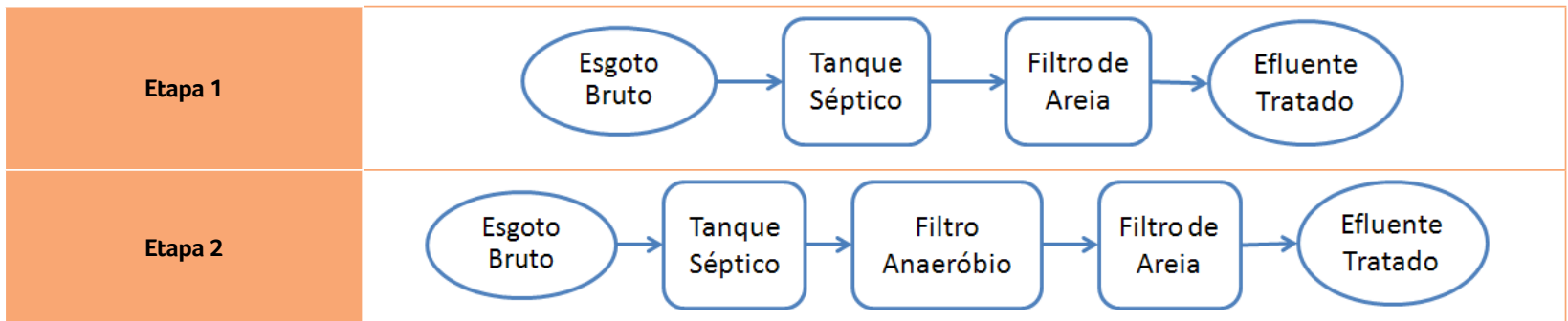

Nos dias da coleta dos efluentes para as análises laboratoriais era avaliada a vazão de geração de esgoto. Para isso foi instalado um hidrômetro na tubulação descarte do efluente tratado.

\subsection{Coleta de Amostras e Análises Laboratoriais}

Foram coletadas amostras dos seguintes pontos de coleta: efluente do tanque séptico, filtro anaeróbio e filtro de areia. Para cada amostra 
eram feitas as seguintes análises: $\mathrm{pH}$, alcalinidade, oxigênio dissolvido (OD), turbidez, série de sólidos, DQO, DBO, compostos nitrogenados, fósforo e coliformes termotolerantes. Todas as análises foram realizadas no Laboratório de Saneamento da Faculdade de Engenharia Civil, Arquitetura e Urbanismo da UNICAMP (LABSAN), baseadas em APHA et al. (2012).

Foi verificada a presença e a redução da viabilidade de ovos de helmintos no esgoto bruto e nos efluentes dos filtros anaeróbios e filtros de areia, assim como nos lodos gerados e no leito de areia. Para isso era utilizada a metodologia para avaliação de helmintos preconizada pela CONAMA 375 (2006), além de se verificar a ocorrência dos protozoários intestinais por meio da metodologia preconizada por Meyer (1978).

Os resultados obtidos foram submetidos a um tratamento estatístico e os dados eram analisados quanto a variância e as médias comparadas por meio do teste de Kruskal-Wallis ao nível de $5 \%(p \leq 0,05)$.

\section{RESULTADOS}

Por meio de monitoramento ao longo do estudo, constatou-se que no local onde estava instalado o sistema de tratamento houve um consumo médio de $1123 \pm 373 \mathrm{~L} . d i a^{-1}$ de água potável. A produção de esgoto chegou a $295 \pm 247$ L.dia $^{-1}$. Desse modo, a razão entre a produção de esgoto e o consumo de água foi de apenas $26 \pm 34 \%$. Esse baixo valor para o coeficiente de retorno (C) pode ser explicado pelo direcionamento de grande volume de água potável para o processo produtivo e limpeza do piso da empresa, além da rega de jardim.

A vazão diária de esgoto era mensurada após a passagem pelo filtro de areia, representando o montante de água residual que realmente foi tratada. Como esse reator possuía uma área su- perficial de 2,84 $\mathrm{m}^{2}$, tem-se que em média havia a disposição de uma taxa de $104 \mathrm{Lm}^{-2} \mathrm{dia}^{-1}$. 0 valor é bastante inferior ao inicialmente estipulado para o dimensionamento do filtro de areia (500 $\left.\mathrm{Lm}^{-2} \mathrm{dia}^{-1}\right)$. Essa diferença deveu-se possivelmente a dois fatores: a) o citado uso da água no processo produtivo e limpeza do piso da indústria; b) um consumo de água pelos funcionários inferior a $70 \mathrm{Ldia}^{-1}$, ou seja, abaixo do estipulado pela NBR 7229 (1993) para empresas onde o funcionário não prepara sua própria alimentação.

Desse modo, as informações levantadas neste trabalho poderão contribuir para fomentar novas pesquisas que avaliem o consumo de água e produção de esgoto em casas ou indústrias que possuam seu próprio sistema de tratamento. Caso contrário, seguindo as orientações da NBR 7229 (1993), será mantida a construção de sistemas descentralizados superdimensionados.

No entanto, o maior consumo de água e consequente geração de esgoto ocorria durante o período de operação da empresa, entre as 8 h00 e as 17 h00. O filtro de areia recebia uma taxa diária média de aplicação de $103 \mathrm{Lm}^{-2} \mathrm{dia}^{-1}$, porém todo o esgoto chegava ao sistema de forma concentrada, entre as $8 \mathrm{~h} 00$ e às $17 \mathrm{~h} 00$. Logo, pode-se afirmar que a taxa de aplicação real foi superior ao valor diário médio. No intervalo entre as $8 \mathrm{h00}$ e as $17 \mathrm{h00}$ (9 horas), o filtro de areia recebia a disposição de $295 \mathrm{~L}$ de esgoto sobre sua superfície, equivalente a taxa de $277 \mathrm{Lm}^{-2} \mathrm{dia}^{-1}$. Esse valor é muito superior ao recomendado pela NBR 13969 (1997). Essa norma sugere que, ao se utilizar o filtro de areia no pós-tratamento de efluente anaeróbio, a taxa de aplicação deve se limitar a $100 \mathrm{Lm}^{-2} \mathrm{dia}^{-1}$. Por sua vez, a USEPA recomenda taxas superiores às da norma brasileira, variando entre 80 e $200 \mathrm{Lm}^{-2} \mathrm{dia}^{-1}$.

Conforme será discutido nos itens seguintes, apesar de essa taxa de aplicação efetiva ser maior do que as apresentadas pela norma bra- 
sileira e dos EUA, o efluente sempre se mostrou com excelente qualidade.

\subsection{Manutenção do Sistema}

Em média, na Etapa 1 até o momento do entupimento transcorriam 10 semanas. Na Etapa 2, na qual foi posta em operação a associação do tanque séptico ao filtro anaeróbio e filtro de areia, houve uma ampliação do tempo demandado até que existisse o entupimento. Em média foram necessárias 20 semanas para a obstrução do fluxo do afluente, o dobro do encontrado para a Etapa 1. Pode-se observar que o primeiro benefício do acréscimo do filtro anaeróbio a esse sistema de tratamento seria a diminuição da frequência de manutenção do leito de areia.

Uma explicação para esse comportamento pode ser a diminuição da concentração de sólidos suspensos propiciada pelo filtro anaeróbio. No caso, a remoção chegou a $70 \pm 11 \%$ (Tabela 4 ), caindo de $134 \pm 40$ (efluente do tanque séptico) para $40 \pm 20 \mathrm{mgL}^{-1}$ (efluente da combinação do tanque séptico + filtro anaeróbio).

É importante destacar que a manutenção do leito exigia apenas a raspagem de uma camada de $5 \mathrm{~cm}$ da sua superfície, possibilitando o pleno restabelecimento do bom funcionamento do sistema de tratamento. Esse resultado está coerente com as afirmações de Rodgers et al. (2005). Esses autores constataram que a formação de biomassa na camada superficial aumenta o tempo de retenção e reduz a área efetiva para o fluxo de líquido, além de alterar a capacidade hidráulica e a taxa de infiltração. Por sua vez, ao utilizar colunas de areia, Kristiansen (1981) notou que a perda de infiltração incidia principalmente nos primeiros $2 \mathrm{~cm}$ do solo, resultante dos sólidos e da atividade biológica. 0 restante do leito permanecia praticamente inalterado.

Após a conclusão da Etapa 1 (Tanque Séptico + Filtro de Areia) e antes de iniciar a Etapa 2 (Tanque Séptico + Filtro Anaeróbio + Filtro de Areia) decidiu-se pela completa troca da areia. No caso, foi empregada uma areia com as mesmas características da utilizada na Etapa 1. A substituição do material filtrante visou ao início da operação dos filtros de areia em condições semelhantes as existentes na Etapa 1. Também foi feita a remoção do lodo do interior do tanque séptico. No caso, como o sistema estava em operação havia quase um ano, poderia ocorrer o arraste desse material para fora do reator, comprometendo os dados gerados pela nova associação de reatores em estudo.

\subsection{Parâmetros físicos e químicos}

A média da temperatura encontrada para o ambiente e para o esgoto foi de $22,6 \pm 3,7^{\circ} \mathrm{C}$ e $23,7 \pm 2,4^{\circ} \mathrm{C}$, respectivamente. Deste modo, não houve ao longo do desenvolvimento da pesquisa dados para o efluente anaeróbio e efluente dos filtros de areia que indicassem alguma interferência da temperatura sobre o tratamento, causando algum prejuízo a qualidade dos efluentes.

Ao longo de toda a pesquisa (Etapas 1 e 2), o pH do efluente do tanque séptico e do filtro de areia sempre se manteve próximo à neutralidade (Tabela 4). Após a partida do filtro anaeróbio na Etapa 2, seu efluente também se manteve próximo à neutralidade $(7,5 \pm 0,2)$. Tais resultados demonstram a estabilidade do sistema no tocante ao $\mathrm{pH}$. Além disso, Chernicharo (2008) considera que os valores de $\mathrm{pH}$ compreendidos entre 6,0 e 8,0 são adequados para o bom funcionamento dos sistemas anaeróbios. 
Tabela 4 - Dados para a construção do tanque séptico e filtro anaeróbio

\begin{tabular}{|c|c|c|c|c|}
\hline Parâmetro & Tanque Séptico & Filtro Anaeróbio & Etapa 1 & Filtro de Areia \\
\hline $\mathrm{SST}\left(\mathrm{mgL}^{-1}\right)$ & $134 \pm 40$ & $40 \pm 20$ & $27 \pm 14$ & $16 \pm 8$ \\
\hline $\mathrm{pH}$ & $7,3 \pm 0,2$ & $7,5 \pm 0,2$ & $7,5 \pm 0,3$ & $7,3 \pm 0,3$ \\
\hline Alcalinidade total $\left(\mathrm{mgCaCO}_{3} \mathrm{~L}^{-1}\right)$ & $567 \pm 106$ & $408 \pm 36$ & $486 \pm 62$ & $288 \pm 75$ \\
\hline Turbidez $(\mathrm{UT})$ & $358,5 \pm 354,5$ & $113,750,0$ & $3,7 \pm 2,1$ \\
\hline $\mathrm{OD}\left(\mathrm{mgL}^{-1}\right)$ & $0,4 \pm 0,2$ & $0,5 \pm 0,2$ & $4,8 \pm 1,5$ & $4,4 \pm 1,0$ \\
\hline $\mathrm{DQO}\left(\mathrm{mgL}^{-1}\right)$ & $423 \pm 123$ & $183 \pm 35$ & $109 \pm 62$ & $81 \pm 6$ \\
\hline $\mathrm{DBO}\left(\mathrm{mgL}^{-1}\right)$ & $125 \pm 26$ & $40 \pm 22$ & $21 \pm 8$ & $17 \pm 11$ \\
\hline $\mathrm{N}-\mathrm{NTK}\left(\mathrm{mgL}^{-1}\right)$ & $144,1 \pm 40,1$ & $91,2 \pm 33,0$ & 113,6 & 27,5 \\
\hline $\mathrm{N}-\mathrm{NO3}-\left(\mathrm{mgL}^{-1}\right)$ & $3,3 \pm 1,3$ & $2,7 \pm 1,5$ & $15,0 \pm 5,9$ & $69,3 \pm 42,7$ \\
\hline Fósforo $\left(\mathrm{mgL}^{-1}\right)$ & $13,0 \pm 9,6$ & $9,3 \pm 2,8$ & $8,0 \pm 3,6$ & $4,4 \pm 2,6$ \\
\hline Ecoli $\left(\mathrm{NMP}^{\left.-100 \mathrm{~mL}^{-1}\right)}\right.$ & $2,7 \times 10^{5} \pm 2,3 \times 10^{5}$ & $1,8 \times 10^{5} \pm 2,2 \times 10^{5}$ & $9,2 \times 10^{3} \pm 2,2 \times 10^{3}$ & $1,0 \times 10^{3} \pm 2,4 \times 10^{3}$ \\
\hline
\end{tabular}

Quanto ao filtro de areia, não foi observada qualquer queda dos valores de $\mathrm{pH}$. Pode ser notado que seu valor médio, em muitos casos, foi ligeiramente superior ao encontrado no efluente do tanque séptico e filtro anaeróbio. Esse comportamento diferencia-se daquele encontrado por Tonetti et al. (2012). Os autores empregaram um sistema semelhante de tratamento e encontraram $\mathrm{pH}$ muito inferiores no efluente do filtro de areia $(<4,0)$. Segundo os pesquisadores, essa queda dos valores de $\mathrm{pH}$ foi resultante do acentuado processo de nitrificação que ocorria no leito de areia, que atingia $100 \%$ dos compostos nitrogenados. No presente estudo, a nitrificação foi bastante tímida, atingindo no máximo $15,5 \pm 5,6 \%$ do nitrogênio total na Etapa 1 e $50,6 \pm 16,7 \%$ na Etapa 2 .

No tocante à alcalinidade total, para toda a Etapa 1 o efluente do tanque séptico apresentou uma média igual a $567 \pm 106 \mathrm{mgCaCO}_{3} \mathrm{~L}^{-1} . \mathrm{Na}$ Etapa 2 houve uma queda significativa da média, chegando a $408 \pm 36 \mathrm{mgCaCO}_{3} \mathrm{~L}^{-1}$. Uma possível explicação para esse comportamento pode estar relacionada a retirada do lodo ao final da Etapa1.

O efluente do filtro de areia atingiu uma alcalinidade igual a $486 \pm 62 \mathrm{mgCaCO}_{3} \mathrm{~L}^{-1}$ na Etapa 1 . Não foi notada diferença significativa entre os valores do efluente do tanque séptico e do filtro de areia (Tabela 4), apontando para um pequeno desempenho da nitrificação. Na Etapa 2 percebe-se que houve uma queda na alcalinidade do efluente do filtro de areia, comparativamente aos valores encontrados no efluente do filtro anaeróbio. Assim como para o $\mathrm{pH}$, esses menores valores de alcalinidade estão correlacionados à ampliação da nitrificação no leito de areia. Esses resultados apontam que a associação do tanque séptico ao filtro anaeróbio gera um efluente com melhores características para a ocorrência da nitrificação no leito de areia.

Cabe destacar que os valores de alcalinidade encontrados para o efluente dos filtros de areia em todo o estudo são muito superiores aos encontrados por Tonetti et al. (2012). Esses autores obtiveram uma alcalinidade total média para o efluente do reator anaeróbio igual a 208 $\pm 55 \mathrm{mgCaCO}_{3} \mathrm{~L}^{-1}$. Para o efluente de um conjunto de filtros de areia, esses pesquisadores sempre obtiveram valores próximos a zero.

Pode-se notar que a alcalinidade encontrada no efluente do tanque séptico foi muito superior à considerada típica, a qual segundo von Sperling (2005) oscila entre 100 e $250 \mathrm{mgCaCO}_{3} \mathrm{~L}^{-1}$. Uma possível explicação para essa diferença de resultados pode estar associada à baixa diluição do esgoto existente em sistemas que tratam águas residuais de pequenas comunidades, tal como o existente na presente pesquisa. Nas regiões onde 
há grande geração de esgotos, ocorre uma maior possibilidade de alto consumo de água per capita e, consequentemente, uma maior diluição do resíduo gerado. Como consequência, os valores de alcalinidade tendem a ser menores. Outra hipótese seria o fato de que em áreas comerciais e indústrias as pessoas envolvidas acabam usando os banheiros com maior frequência para urinar, $\mathrm{e}$ a urina tem alta concentração de ureia e grandes valores de alcalinidade.

É importante discutir se a alcalinidade existente no efluente anaeróbio gerado pelo tanque séptico seria suficiente para suportar a nitrificação de todo o N-NTK no filtro de areia. Segundo Metcalf e Eddy (2003), para 1,00 g de N- $\mathrm{NH}_{4}{ }^{+}$convertido a nitrato, ocorre o consumo de $4,25 \mathrm{~g}$ de $\mathrm{O}_{2}$, formando $0,16 \mathrm{~g}$ de novas células a partir da utilização de 0,08 g de carbono inorgânico, além de diminuir em 7,07 $\mathrm{g}$ a alcalinidade como $\mathrm{CaCO}_{3}$ do meio. Como o efluente dos reatores anaeróbios do presente estudo possuía 91,2 $\pm 33,0 \mathrm{mgL}^{-1}$ de N-NTK haveria um consumo de $640 \mathrm{mgL}^{-1}$ de alcalinidade na forma de carbonato. Logo, tal como se deu com Tonetti et al. (2012), haveria a necessidade do aporte de um composto alcalino. Caso contrário haveria o comprometimento do $\mathrm{pH}$, tornando-o ácido e, possivelmente, prejudicial ao próprio tratamento.

A ocorrência de uma nitrificação apenas parcial pode ser um fator positivo para sistemas descentralizados. Caso ocorresse a completa transformação dos compostos nitrogenados a nitrato, possivelmente haveria o comprometimento da qualidade do efluente no que tange ao $\mathrm{pH}$. Esse fato poderia inclusive impedir seu lançamento em corpos hídricos ou mesmo o reúso. Cabe destacar que o pH está presente no padrão de lançamento em corpos hídricos ( 6 a 9), enquanto a concentração de nitrato faz parte apenas do padrão de enquadramento (CONAMA 357, 2005).
No tocante à análise de sólidos suspensos totais (SST), pode-se perceber por meio da Tabela 4 que o efluente do filtro de areia apresentava uma concentração sem diferença significativa entre as duas etapas deste estudo. Deste modo, a inclusão do filtro anaeróbio não acarretou benefício à qualidade do efluente final quanto a este parâmetro. No entanto, observa-se claramente que o filtro anaeróbio propiciou uma significativa remoção de sólidos na Etapa 2, chegando a $70 \pm 31 \%$.

Essa remoção de sólidos pelo filtro anaeróbio não trouxe benefícios à qualidade do efluente do filtro de areia, porém foi extremamente positiva quanto à manutenção do leito de areia. Como anteriormente discutido, aplicando o efluente proveniente do tanque séptico, após 10 semanas havia o entupimento do leito de areia, enquanto empregando o efluente provindo do filtro anaeróbio o entupimento dava-se após 20 semanas.

A baixa concentração de sólidos suspensos também seria benéfica para o reúso na agricultura devido à menor possibilidade de entupimento dos equipamentos utilizados na irrigação, tal como gotejador. Capra e Scicolone (2004) afirmam que há baixo risco de obstrução dos gotejadores quando a concentração final de SST for inferior a $50 \mathrm{mgL}^{-1}$. Logo, em todos os casos o efluente do filtro de areia atenderia a esse requisito.

Como consequência da remoção de sólidos suspensos, o filtro de areia também foi muito eficiente na remoção de turbidez (Tabela 4). $O$ efluente do tanque séptico apresentava valores médios iguais a $358,5 \pm 354,5$ UT, enquanto o filtro de areia gerava um efluente com valores muito inferiores, com média mínima na Etapa 1 igual a 3,8 \pm 1,5 UT e 3,7 $\pm 2,1$ UT na Etapa 2. Nesses casos, a remoção chegou a 99,0 $\pm 2,4 \%$ e $96,7 \pm 1,8 \%$.

Esses baixos valores de turbidez e de sólidos suspensos totais permitem que na desinfecção do efluente haja a demanda por uma menor quantidade de cloro, logo será barateada algu- 
ma possibilidade de reúso seguro desse esgoto tratado. Desse modo, um diferencial importante do emprego de filtro de areia seria a garantia da geração de um efluente de excelente qualidade e com um aspecto e odor que não causa aversão ao ser humano.

Quanto ao OD, destaca-se a grande capacidade dos filtros de areia em oxigenar o líquido tratado. Para todas as Etapas, 1 e 2, a média foi de 4,6 $\pm 1,2 \mathrm{mgL}-1$. Essa aeração do efluente foi ocasionada pela operação intermitente do filtro de areia, garantida pela ação do sifão instalada a montante do reator. Entre uma aplicação e outra de afluente anaeróbio havia a possibilidade do preenchimento do leito com ar atmosférico.

No tocante à DQO do efluente do tanque séptico, foram encontrados valores médios iguais a $423 \pm 123 \mathrm{mgO}_{2} \mathrm{~L}^{-1}$ (Etapa 1). Deve-se lembrar de que não foi avaliada a eficiência da remoção de matéria orgânica nesse reator, visto que o afluente percorria um trajeto muito curto entre a geração e a entrada no sistema de tratamento. $\mathrm{Na}$ Etapa 1, para o efluente do filtro de areia, obteve-se uma DQO igual a $109 \pm 62 \mathrm{mgO}_{2} \mathrm{~L}^{-1}$.

$\mathrm{Na}$ Etapa 2 o filtro anaeróbio propiciou uma diminuição de $57 \pm 7 \%$ nos valores de DQQ , a qual atingiu a média de $183 \pm 35 \mathrm{mgO}_{2} \mathrm{~L}^{-1}$. Esse valor é bastante superior ao limite estipulado pela legislação do Estado de Minas Gerais (COPAM no1, 2008) e pela legislação aplicada na comunidade europeia (Diretiva 91/271/CEE). Elas apresentam os limites de 120 e $125 \mathrm{mgO}_{2} \mathrm{~L}^{-1}$ para o lançamento em corpos hídricos.

Ao avaliar a DBO do efluente deste reator, sua média chegou a $40 \pm 22 \mathrm{mgO}_{2} \mathrm{~L}^{-1}$. Esse resultado confirma Chernicharo (2008) e Gonçalves et al. (2001), que afirmam que a combinação do tanque séptico ao filtro anaeróbio é capaz de gerar um efluente que atende a padrões mais restritivos de lançamento, como a legislação do Estado de São Paulo (DECRETO Nº 8.468, 1976), que exige o limite de $60 \mathrm{mgL}^{-1}$.

Mesmo com a entrada em operação do filtro anaeróbio não houve influência significativa no tratamento propiciado pelos filtros de areia. A eficiência de remoção média saltou de $83 \pm 14 \%$ na Etapa 1 para $86 \pm 7 \%$ na Etapa 2. Não existia diferença significativa entre as médias das DQQO (Tabela 4). Desse modo, há uma forte indicação de que a presença de um filtro anaeróbio após um tanque séptico não leva a uma melhoria do pós-tratamento em filtros de areia no tocante à remoção de matéria orgânica.

A DBO efluente ao filtro de areia na Etapa 2 atingiu uma média de somente $17 \pm 11 \mathrm{mgO}_{2} \mathrm{~L}^{-1}$, muito inferior ao limite máximo estipulado pela legislação do Estado de São Paulo (DECRETO Nº 8.468, 1976).

Nos EUA, Widrig et al. (1996) testaram espessuras de leito entre 0,31 m e 1,63 m e carga hidráulica de somente $76 \mathrm{Lm}^{-2} \mathrm{dia}^{-1}$ de esgoto. No experimento, os autores encontraram DBO no efluente do filtro mais raso de $11,0 \mathrm{mgL}^{-1} \mathrm{e}$ no mais profundo de $2,5 \mathrm{mgL}^{-1}$, permitindo que chegasse à conclusão de que as profundidades superiores a 0,90 m não propiciavam vantagens ao tratamento. Na Irlanda, Rodgers et al. (2005) estudaram o emprego de esgoto doméstico em duas diferentes taxas de aplicação em colunas de areia de 0,425 e 0,900 m de profundidades. Eles obtiveram, ao utilizar $42 \mathrm{Lm}^{-2} \mathrm{dia}^{-1}$, uma remoção de $67 \%$ em termos de DBO na coluna mais rasa e $77 \%$ na mais profunda.

Comparativamente, na presente pesquisa foram aplicadas cargas hidráulicas de $277 \mathrm{Lm}^{-2} \mathrm{dia}^{-1}$, cerca de 3,6 vezes superior à adotada por Widrig et al. (1996) e 6,6 vezes maior que a empregada por Rodgers et al. (2005). No entanto, os resultados de DBO e DQOO no efluente dos filtros de areia foram extremamente próximos ao dos autores citados. Isso demonstra que o dimensiona- 
mento desse sistema em países de clima tropical, como o Brasil, não pode ser profundamente influenciado por normas estrangeiras.

\subsection{Nitrogênio e fósforo}

No tocante aos compostos nitrogenados, o NTK na Etapa 1 atingiu a média de $144,1 \pm 40,1 \mathrm{mgL}^{-1} \mathrm{e}$ na Etapa 2 chegou a 91,2 $\pm 33,0 \mathrm{mgL}^{-1}$ no efluente do tanque séptico e filtro anaeróbio. Esses dados estão muito acima da faixa apontada por von Sperling (1996) como típica para águas residuais de origem doméstica, que possui como limites as concentrações de 35 e $70 \mathrm{mgL}^{-1}$. Também são superiores aos encontrados por Tonetti et al. (2012). Tal como a alcalinidade, essas altas concentrações podem ser fruto da pequena diluição do esgoto de pequenos grupamentos humanos. Além do que, como se trata de uma empresa, o banheiro é utilizado pelos funcionários principalmente para urinar, e não defecar.

Após a passagem pelo filtro de areia, houve um aumento na concentração de nitrato (Tabela 4), fruto da nitrificação. Na Etapa 1 a nitrificação atingiu somente 10,0 $\pm 9,3 \%$ do $N$-Total. Como explicação desse comportamento, de imediato pode ser descartada a hipótese da falta de aeração do meio, visto que a concentração de oxigênio dissolvido não apresentou diferença significativa nas três fases da Etapa 1.

Uma hipótese para essa baixa eficiência poderia ser a concentração de N-NTK afluente ao filtro de areia, que chegou à média de $144,1 \pm 40,1 \mathrm{mgL}^{-1}$ na Etapa 1, a qual foi muito superior a existente no estudo conduzido por Tonetti et al. (2012), que empregaram uma água residual que apresentava concentração de N-Total igual a 48,1 \pm $9,6 \mathrm{mgL}^{-1}$. Esses mesmos autores encontraram uma completa nitrificação do afluente anaeróbio aplicado na superfície de leitos de areia.
Após a introdução do filtro anaeróbio no sistema de tratamento (Etapa 2), nota-se que a nitrificação foi mais expressiva, chegando à média de $69,3 \pm 42,7 \mathrm{mgL}^{-1}$ ou o equivalente a 76,0 \pm $16,7 \%$ do N-Total. Uma possível explicação para essa melhoria do desempenho na Etapa 2 em comparação ao obtido na Etapa 1 seria a criação de condições mais adequadas para as bactérias nitrificantes competirem com as heterotróficas. No caso, o filtro anaeróbio removeu $55 \pm 7 \%$ nos valores de DQO presentes no efluente do tanque séptico, diminuindo a disponibilidade de matéria orgânica nos filtros de areia.

O menor desempenho para a nitrificação quando comparado ao estudo conduzido por Tonetti et al. (2012) e Magalhães et al. (2016) poderia ser fruto da menor profundidade do leito de areia. $\mathrm{Na}$ presente pesquisa foi adotado o valor de 0,40 $\mathrm{m}$, enquanto Tonetti et al. (2012) empregaram $0,75 \mathrm{~m}$ e obtiveram a completa nitrificação dos compostos nitrogenados. Porém, buscando compreender a evolução do tratamento do afluente ao longo da infiltração em um leito de areia, Pell e Nyberg (1989) coletaram amostras em diversas profundidades a partir da superfície de filtros de areia e concluíram que a nitrificação se deu a poucos centímetros da superfície do leito. Abaixo de $15 \mathrm{~cm}$ não foram encontradas mudanças significativas. Em experimento similar conduzido por Ellis (1987), constatou-se que $50 \%$ da nitrificação e remoção dos sólidos ocorriam igualmente na camada superficial.

Desse modo, a literatura não indica que a profundidade adotada seja uma explicação adequada para a menor eficiência da nitrificação obtida nesta escala real quando comparada à piloto (TONETTI et al. 2012).

A concentração de fósforo presente no efluente do tanque séptico ao longo de toda a pesquisa era de 10,5 $\pm 2,9 \mathrm{mgL}^{-1}$. Esse valor está muito acima daquele encontrado por Tonetti et al. (2012), 
os quais encontraram uma concentração de apenas 3,3 $\pm 0,9 \mathrm{mgL}^{-1}$. No entanto, está dentro da faixa apresentada por von Sperling (1996) como típica para esgotos domésticos, a qual varia entre 5 e $25 \mathrm{mgL}^{-1}$.

O filtro de areia propiciou uma eficiência de remoção tendendo ao decréscimo ao longo do estudo. No decorrer das semanas havia uma tendência a aumentar a concentração de fósforo até atingir o entupimento. Possivelmente esse comportamento pode estar ligado à contínua saturação da capacidade do leito de areia em adsorver esse composto.

Após cada entupimento ocorria a retirada da camada superficial do leito e a reposição com areia nova. Essa ação trazia como benefício o retorno a uma alta remoção de fósforo. Novamente, essa capacidade foi diminuindo ao longo das semanas. Desse modo, o aumento da concentração de fósforo no efluente pode ser um indicativo químico da existência de entupimento do leito de areia.

\subsection{Escherichia Coli e Patógenos}

No tocante à densidade de Escherichia coli, a remoção propiciada pelos filtros de areia nas composições avaliadas foi de apenas 2 unidades logarítmicas (Tabela 4). Esses valores associados à pequena turbidez encontrada possibilitarão que baixas dosagens de cloro levarão a rápida eliminação destes organismos indicadores de contaminação fecal (LEONEL et al., 2016).

Stevik e Ausland (2004) e Bancolé (2001) obtiveram uma remoção de microrganismos em filtros de areia entre 2 e 6 unidades logarítmicas. Segundo os autores, a remoção ocorria devido à retenção e à degradação. Na retenção estão envolvidos os mecanismos físicos de filtração mecânica, enquanto na degradação o microrganismo é exposto a um conjunto de fatores abióticos e bióticos desfavoráveis. Entre os bióticos está a presença de predadores, principalmente de protozoários (STEVIK et al., 2004).

Nos efluentes do tanque séptico, filtro anaeróbio e filtro de areia não foram detectados ovos de helmintos. Possivelmente esse resultado pode estar associado à inexistência de algum indivíduo infectado por esse parasita. Mesmo a areia retirada após a manutenção dos leitos não apresentou qualquer contaminação.

De forma geral, ao comparar os resultados obtidos com os valores microbiológicos sugeridos pela OMS (2000) para uso de esgoto doméstico tratado em culturas, constata-se que nenhum dos efluentes estaria adequado para irrigação de culturas que sejam comidas sem cozimento, campos esportivos e parques públicos. Nesse caso, a densidade máxima de coliformes fecais permitida é de $10^{3} \mathrm{NMP} 100 \mathrm{~mL}^{-1}$. No entanto, seria viável para a irrigação de cereais e culturas a serem industrializadas, silviculturas, árvores frutíferas e forrageiras para feno e silagem, nas quais se exige um efluente com densidade limite de $10^{5} \mathrm{NMP} 100 \mathrm{~mL}^{-1}$.

\section{CONCLUSÕES}

Os resultados da presente pesquisa apontam para a necessidade de revisão dos critérios de dimensionamento de sistemas simplificados de tratamento de esgoto. Possivelmente deverá ser considerada a geração de menores volumes de esgoto per capita em empresas ou localidades isoladas e considerar o real período das atividades produtivas e de produção da água residual.

O uso do filtro anaeróbio após o tanque séptico acarreta um período maior de uso do filtro de areia sem o entupimento da camada superficial do leito de areia (20 semanas). O filtro anaeróbio gera um efluente que cria condições para uma maior ocorrência da nitrificação no leito de areia. 
A DBO do efluente do filtro de areia foi de somente $17 \pm 11 \mathrm{mgO} 2 \mathrm{~L}-1$, inferior ao limite estipulado pela legislação do Estado de São Paulo (DECRETO No 8.468, 1976). A adoção do filtro anaeróbio após o tanque séptico não beneficiou a remoção de DQQO.

O sistema composto por tanque séptico, filtro anaeróbio e filtro de areia não deve ser projetado seguindo orientações de pesquisas ou órgão ambientais de países com clima mais frio que o brasileiro. Na presente pesquisa foram dispostas cargas hidráulicas até 6,6 vezes superiores às adotadas na Europa, mas houve a geração de efluente compatível com o de sistemas similares instalados na Irlanda e EUA.

Ao longo do uso do filtro de areia havia a tendência de queda da eficiência da remoção de fósforo, até o entupimento da superfície do leito de areia. Possivelmente, a capacidade de adsorção de fósforo pelo leito de areia não foi proveniente principalmente da adsorção química da areia, mas devido à incorporação ao biofilme.

\section{AGRADECIMENTOS}

Agradecemos à Capes e ao CNPq (311275/20150) pelas bolsas de mestrado e doutorado recebidas e à Fapesp (Processo 2017/07490-4) pelo Auxílio à Pesquisa.

\section{CONTRIBUIÇÃO DOS AUTORES}

Todos os autores contribuíram de forma igualitária.

\section{REFERÊNCIAS}

ALÉM SOBRINHO, P.; SAID, M. A. Decanto digestor e filtro anaeróbio, experiência de campo. Proposições para alteração do método de dimensionamento do filtro anaeróbio proposto pela NBR 7229. In: Congresso Brasileiro de Engenharia Sanitária e Ambiental, Associação Brasileira de Engenharia Sanitária (ABES), 1991. Anais...
APHA/AWWA/WEF. Standard methods for the examination of water and wastewater. 19a edição. Nova lorque: American Public Health Association. 2005.

CAMARGO, S. A. R., NOUR, E. A. A. (2001) Bamboo as an anaerobic medium: effect of filter column height. Water Sci Technol 44:63-70

CHERNICHARO, C. Reatores Anaeróbios. 1a edição. Belo Horizonte, UFMG. 2008.

CONAMA - CONSELHO NACIONAL DE MEIO AMBIENTE. Resolução número 430. Dispõe sobre a classificação dos corpos de água e diretrizes ambientais para o seu enquadramento. Ministério do Desenvolvimento e Meio Ambiente. 2011.

CONAMA - CONSELHO NACIONAL DE MEIO AMBIENTE. Resolução número 357. Dispõe sobre a classificação dos corpos de água e diretrizes ambientais para o seu enquadramento. Ministério do Desenvolvimento e Meio Ambiente. 2005.

CONAMA - CONSELHO NACIONAL DO MEIO AMBIENTE. Resolução número 375. Define critérios e procedimentos, para o uso agrícola de lodos de esgoto gerados em estações de tratamento de esgoto sanitário e seus produtos derivados, e dá outras providências. Ministério do Desenvolvimento Urbano e Meio Ambiente. 2005 .

COPAM - Conselho Estadual De Política Ambiental (2008) Deliberação Normativa ${ }^{\circ} 1$. Diário do Executivo de Minas Gerais, Minas Gerais.

DE OLIVEIRA CRUZ, L. M.; STEFANUTTI, R.; FILHO, B. C.; TONETTI, A. L. Coconut shells as filling material for anaerobic filters. SpringerPlus, v. 2, p. 655, 2013. https://doi.org/10.1186/2193-1801-2-655

DE OLIVEIRA CRUZ, L. M.; TONETTI, A. L.; GOMES, B. G. L. A. Association of septic tank and sand filter for wastewater treatment: full-scale feasibility for decentralized sanitation. Journal of Water Sanitation and Hygiene for Development, v. 8, p. washdev2018094-277, 2018. https://doi.org/10.2166/ washdev.2018.094

DE OLIVEIRA CRUZ, L. M.; GOMES, B. G. L. A.; TONETTI, A. L.; FIGUEIREDO, I. C. S. Using coconut husks in a full-scale decentralized wastewater treatment system: The influence of an anaerobic filter on maintenance and operational conditions of a sand filter. Ecological engineering, v. 127, p. 454-459, 2019. https://doi.org/10.1016/j.ecoleng.2018.12.021

FIGUEIREDO, I. C. S.; MIYAZAKI, C. K.; MADRID, F. J. P. L.; DUARTE, N. C.; MAGALHÃES, T. M.; TONETTI, A. L. Fossa absorvente ou rudimentar aplicada ao saneamento rural: solução adequada ou alternativa precária? Revista DAE, v. 67, p. 87-99, 2019. https://doi. org/10.4322/dae.2019.057

IBGE. INSTITUTO BRASILEIRO DE GEOGRAFIA E ESTATíSTICA. Pesquisa Nacional de Saneamento Básico. Rio de Janeiro. 2008. 
LEONEL, L. P.; TONETTI, A. L.; SILVA, J. C. P.; NUNES, E. A.; ANARUMA FILHO, F. Reuse of sewage treated effluent in agricultural practices: An alarming presence of Giardia spp. cysts. Ecological Engineering, v. 94, p. 682-687, 2016. https://doi.org/10.1016/j. ecoleng.2016.06.126

MAGALHÃES, T. M.; TONETTI, A. L.; BUENO, D. A. C.; TONON, D. Nitrification process modeling in intermittent sand filter applied for wastewater treatment. Ecological Engineering, v. 93, p. 1823, 2016. https://doi.org/10.1016/j.ecoleng.2016.05.003

MEYER, Y.B. Recovery of Ascaris eggs from sludge. Journal of Parasitology. Volume 64, número 2, pp. 380-383. 1978.

NBR 7229 - Projeto, construção e operação de tanques sépticos. São Paulo, ABNT. 1993.

NBR 13969 - Tanques sépticos - Unidades de tratamento complementar e disposição final dos efluentes líquidos. São Paulo, ABNT. 1997.

RODGERS, M.; HEALY, M. G.; MULQUEEN, J. Organic carbon removal and nitrification of high strength wastewaters using stratified sand filters. Water Research, no 39, pp. 3279-3286. 2005.

TONETTI, A. L.; CORAUCCI FILHO, B.; GUIMARÃES, J. R.; CRUZ, L. M. O.; NAKAMURA, M. S. Avaliação da partida e operação de filtros anaeróbios tendo bambu como material de recheio. Revista Engenharia Sanitária e Ambiental, v.16 n.1, p 11-16. 2011. https:// doi.org/10.1590/S1413-41522011000100004
TONETTI, A. L., CORAUCCI FILHO, B., NICOLAU, C. E., BARBOSA, M., TONON, D. (2012) Tratamento de esgoto e produção de água de reúso com o emprego de filtros de areia. Revista Engenharia Sanitária e Ambiental 17(1):287-294. https://doi.org/10.1590/ S1413-41522012000300005

TONETTI, A. L.; CORAUCCI FILHO, B.; GUIMARÃES, J. R.; FADINI, P. S. NICOLAU, C. E. (2013) Desnitrificacao em um sistema simplificado de tratamento de esgoto. Revista Engenharia Sanitária e Ambiental 18(4): 381-392. https://doi.org/10.1590/S141341522013000400010

TONON, D; TONETTI, A. L.; CORAUCCI FILHO, B.; BUENO, D. A. C. Wastewater treatment by anaerobic filter and sand filter: $\mathrm{Hy}$ draulic loading rates for removing organic matter, phosphorus, pathogens and nitrogen in tropical countries. Ecological Engineering, v. 82, p. 583-589, 2015. https://doi.org/10.1016/j.ecoleng.2015.05.018

USEPA - UNITED STATES ENVIRONMENTAL PROTECTION AGEN$\mathrm{CY}$. Onsite wastewater treatment manual. Technology transfer. Washington. 2002.

VAN HAANDEL, A. C. e LETTINGA, G. Tratamento anaeróbio de esgotos. Um manual para regiões de clima quente. 1994.

YOUNG, J. C.; MCCARTY, P. L. The anaerobic filter for waste treatment. Journal of Water Pollution Control Federation. Número 41. 1969. 